\title{
Modelos de Espaço Público em contraste: Imprensa e Modernidade Seletiva nas Províncias da Paraíba e Pernambuco (1870-1880)
}

\author{
Models of Public Space in contrast: Press and Selective Modernity \\ in the Provinces of Paraíba and Pernambuco (1870-1880)
}

\begin{abstract}
Modelos de Espacio Público en contraste: Prensa y Modernidad Selectiva en las Provincias de Paraíba y Pernambuco (1870-1880)
\end{abstract}

\author{
Matheus da CRUZ E ZICA ${ }^{1}$; PATRÍCIA BARRos DE OLIVEIRA ${ }^{2}$
}

\section{Resumo}

Este artigo procura elucidar o debate que se constituiu pela imprensa ao longo das décadas de 1870 e 1880 nas províncias brasileiras da Paraíba e de Pernambuco em torno do modelo francês de monarquia parlamentar que contrastava com o federalismo republicano dos EUA. Assumindo o lugar de formadora da opinião pública a imprensa procurou trazer destaque para a questão do Espaço Público na medida em que modos distintos de se lidar com ele estavam em jogo em cada um daqueles modelos políticos internacionais idealizados. Também foram mapeadas algumas relações que os jornais analisados indiciaram entre os debates sobre o Espaço Público e as retóricas de modernidade que os acompanhavam. Com frequência a questão da ciência e da técnica pareceu eclipsar a dimensão do conflito que é próprio do universo político e da esfera pública, unificando os olhares em torno de um deslumbramento com as benfeitorias materiais que o século prometia.

Palavras chave: Espaço Público, Formação, Imprensa.

\footnotetext{
${ }^{1}$ Doutor em Educação pela Universidade Federal de Minas Gerais. Professor do Centro de Educação da Universidade Federal da Paraíba e da Pós-Graduação em História da Universidade Federal de Campina Grande. E-mail: matheusczica@gmail.com

${ }^{2}$ Mestre em História pela Universidade Federal de Campina Grande. E-mail: pf4303@ hotmail.com
} 


\begin{abstract}
This article seeks to elucidate the debate that was constituted by the press throughout the 1870s and 1880s in the Brazilian provinces of Paraíba and Pernambuco around the French model of parliamentary monarchy that contrasted with the republicanism of the USA. Taking over the role of public opinion maker, the press sought to highlight the issue of the Public Space since that distinct ways of dealing with it was considered in each of those idealized international political models. This article also mapped some relations that the newspapers analyzed betrayed between the debates on the Public Space and the rhetoric of modernity that accompanied them. Often the question of science and technique seemed to eclipse the dimension of conflict that is proper to the political universe and the public sphere, unifying the glances around a dazzle with the material improvements that the century promised.
\end{abstract}

Keywords: Public Space, Formation, Press.

\title{
Resumen
}

Este artículo busca esclarecer el debate que se constituyó por la prensa a lo largo de las décadas de 1870 y 1880 en las provincias brasileñas de Paraíba y de Pernambuco en torno al modelo francés de monarquía parlamentaria que contrastaba con el federalismo republicano de EUA. Asumiendo el lugar de formadora de la opinión pública la prensa trató de destacar la cuestión del Espacio Público en la medida en que modos distintos de lidiar con él estaban en juego en cada uno de aquellos modelos políticos internacionales idealizados. También se han mapeado algunas relaciones que los periódicos analizados indiciaron entre los debates sobre el espacio público y las retóricas de modernidad que los acompañaban. Con frecuencia la cuestión de la ciencia y de la técnica parecía eclipsar la dimensión del conflicto que es propio del universo político y de la esfera pública, unificando las miradas en torno a un deslumbramiento con las mejoras materiales que el siglo prometía.

Palabras clave: Espacio Público, Formación, Prensa. 


\section{Introdução}

O presente artigo tem por intuito elucidar um processo de debate amplo que se desenvolveu e se constituiu pela imprensa em torno de modos de organização do Espaço Público ao longo das décadas de 1870 e 1880 nas províncias brasileiras da Paraíba e de Pernambuco. As disputas políticas em torno do modelo francês de monarquia parlamentar que contrastava com o federalismo republicado dos Estados Unidos da América, trazia em seu bojo um destaque para a questão do Espaço Público na medida em que modos distintos de se lidar com ele estavam em jogo em cada uma dessas propostas.

Grupos políticos se utilizaram da imprensa para exaltarem um modelo internacional ou outro em função da crítica ou defesa que queriam fazer do regime Monárquico brasileiro vigente naquele momento. $\mathrm{O}$ debate público que se confunde em boa medida com a própria dinâmica da liberdade de expressão encarnada pela imprensa se transforma assim, nessa configuração, também em um meio importante de formação de sensibilidades afeitas ao clima de argumentações racionalmente fundamentadas, e a possibilidade da presença de uma pluralidade de visões de mundo coexistindo em um mesmo tempo e espaço.

Nos interessou perceber também as relações que os jornais analisados indiciaram naquela conjuntura histórica entre os debates sobre modos de lidar com o Espaço Público e as retóricas de modernidade que os acompanhavam. Os argumentos em torno dos progressos técnicos tinham forte impacto durante o século XIX, notadamente a partir da segunda metade, alimentados pelas ocorrências das propagandeadas Exposições Universais, de cunho internacionalista. Se pôde notar que com frequência a questão da ciência e da técnica parecia eclipsar a dimensão do conflito que é próprio do universo político e da esfera pública, unificando os olhares em torno de um deslumbramento com o progresso e as benfeitorias materiais que o século prometia.

\section{Idealizações do estrangeiro e projeções de Espaços Públicos possíveis}

No Brasil do século XIX, a experiência da modernidade foi pautada por alguns modelos estrangeiros então em voga. Dentre os mais citados estão o francês, o americano e o alemão. Desses, podemos dizer que na Paraíba, de acordo com as fontes pesquisadas, houve predominância das ideias francesas, pelo menos até a década de 1870, recorte temporal deste artigo. Como paradigmas, essas nações serviam de referência para as demais sobretudo nas formas de pensar, de agir, de ser.

Assim, a política, a legislação, a moda, a educação implantadas no país naquele momento sofreram a influência daquelas sociedades. Ressalte-se, porém, que, mais do que copiar um modo de pensar e um estilo de vida, o Brasil se apropriou dessas ideias, ressignificando-as e representando-as ao seu próprio modo.

Nesse sentido, seguindo os conceitos de apropriação e representação de Roger Chartier (2002, p.47), o foco de nossa análise concentra-se na apreensão de "como um grupo ou um homem 'comum' apropria-se à sua maneira, que pode ser deformadora, das idéias ou das crenças de seu tempo". Essa apropriação produz um discurso que não é neutro e tende, para se legitimar, a menosprezar outros. 
Essa abertura ao estrangeiro, contudo, nem sempre é aceita de bom grado por todos. A interferência do que vinha de fora era consciente e até contestada por algumas pessoas. $\mathrm{O}$ jornal, suporte no qual as ideias de um tempo ganham registro, e, por isso, importante na formação da opinião pública, é responsável por nos ajudar a pintar um cenário do que foi discutido na sociedade de então.

Se no Brasil a inspiração francesa parece ter sido mais forte no âmbito cultural, uma outra forma de experimentar a modernidade, à americana, foi contemporânea à da capital europeia e permeou discussões de cunho mais político, como podemos verificar no jornal recifense $O$ Americano. Idealizado por Tobias Barreto, líder da Escola do Recife, era de responsabilidade também de Minervino A. de S. Leão e do escritor Franklin Távora, membro do movimento.

Como porta-voz das ideias da Escola, defendia ardorosamente o modelo republicano norte-americano, cuja constituição foi esmiuçada nas primeiras edições daquele jornal. Semanário político, era impresso na tipografia de Carlos Eduardo Muhlert, alemão naturalizado brasileiro pelo Decreto n.920 de 26 de agosto de 1857. Essa ligação do jornal com Muhlert nos indica também a presença da influência alemã na produção intelectual de Tobias Barreto, entre elas a jornalística.

Sobre o clima da imprensa pernambucana quando da circulação de $O$ Americano, o pesquisador Cláudio Aguiar (1997, p.123) nos diz que "variava entre os temas do humor, da sátira, da prestação de serviços e divertimentos, da política, quer da partidária índole conservadora, quer da de compromisso liberal com as mudanças sociais, quer das tipicamente radicais, que defendiam profundas alterações no regime vigente - a Monarquia."

Antimonarquista e abolicionista, $O$ Americano circularia, para Aguiar, na esteira radical. Nesse contexto de revisão política, em que se almeja a república, esse jornal assumirá, às vezes, papel de porta-voz dessas novas ideias, oposto ao modelo exportado pela França, país a quem considerava, no aspecto político, antiquado, conforme passagem que se segue:

\section{POLITICA GERAL}

\section{BOLETIM DA SEMANA}

\section{RECIFE, 14 DE MAIO DE 1870}

As ultimas noticias da Europa são, em geral, destituidas de interesse, á excepção das que dizem respeito á França, onde o espirito publico, embalado nas gratas illusões de uma promettida éra de liberdade, que tudo levava a crer inaugurada pelas concessões do imperante sobre o regimen parlamentar, acaba de soffrer uma amarga decepção. Que valeu, decerto, todo esse generoso desinteresse afectado pela corôa e hoje conhecidamente capcioso? Quando se trata de firmar o regimen pela renuncia da terrivel iniciativa, que ao imperante confere a constituição, no exercicio do poder constituinte insiste elle em manter integral em suas mãos uma faculdade arbitrária, que é ao mesmo tempo a mais apropriada arma para aniquilar todas as liberdades parlamentares e produzir os mais desastrosos golpes de estado. Eis ahi, pois, em pleno vigor o governo pessoal e autoritario, julgado um 
momento em retirada pela boa fé publica. Tão certo é que toda a desconfiança é pouca da parte do paiz, quando os tyrannos habituaes se mostram inspirados de outros sentimentos que não sejam só compativeis com o despotismo. (Jornal $O$ Americano, edição 3, $15 / 05 / 1870)$

Pelo que se vê, mesmo sem uma coluna fixa reservada às notícias internacionais, a exemplo de $O$ Liberal Parahybano - do qual falaremos mais adiante -, a $O$ Americano também convinha repercutir em solo brasileiro fatos acontecidos no exterior. Sobre a Europa, particularmente a França, interessam apenas notícias que venham a confirmar o ponto de vista do jornal: a experiência da modernidade vivida à francesa - em especial no campo político não lhes inspira. Ao apontar as falhas daquele país, estariam legitimando, consequentemente, o ideário americano que tanto valorizavam.

No recorte acima, a crítica dirige-se ao governo de Napoleão III, primeiro presidente francês eleito por voto direto. Após ser impedido pela constituição e pelo parlamento de concorrer a um segundo mandato, organizou um golpe em 1851, assumindo o trono como imperador no final de 1852. Num período pós Revolução Francesa, restaurar o império - concentrar o poder - para aqueles que o combatiam aqui, era sinônimo de um grande retrocesso.

Essas cenas retratam a imagem repudiada por $O$ Americano, que não aceitava o regime político nas mãos de uma monarquia constitucional. Mencionado o caso francês, a crítica se estendia a D. Pedro II - cujo sistema de governo configurava um atraso às vistas do jornal recifense - e à Revolução Francesa, cujo ideal de liberdade via com desconfiança. Afinal, a liberdade assegurada pela Revolução foi destinada primordialmente à burguesia.

Segundo José Murilo de Carvalho (2005, p.84), essa discussão sobre organização política foi possível porque para o Brasil, "como país exportador de matérias-primas e importador de idéias e instituições, os modelos de república existentes na Europa e na América, sobretudo nos Estados Unidos e na França, serviram de referência constante [...]."

Acreditamos que essa importação não foi aleatória; foi uma tentativa de implantar no Brasil um modelo que já estava funcionando nos países de origem, que se projetavam muito bem como exemplos. Na leitura de Carvalho (2005, p.90), essa prática de apropriação de modelos de república não foi exclusiva nem do Brasil nem da época moderna:

Idéias e instituições norte-americanas e européias já tinham sido adaptadas por políticos imperiais. Antes mesmo da independência do País, rebeliões coloniais tinham-se inspirado seja na revolução americana, seja na francesa. Importar modelos, ou inspirar-se em exemplos externos, não era, assim, exclusividade dos republicanos brasileiros. Os próprios founding fathers americanos buscaram inspiração em idéias e instituições da Antigüidade, da Renascença, da Inglaterra e França contemporâneas. A Revolução Francesa, por sua vez, tivera nos clássicos e no exemplo americano pontos de referência. O fenômeno de buscar modelos externos é universal. 
Ressalte-se ainda que o ecletismo, durante o Império brasileiro, se fez marcante não somente no tocante à organização política, cuja inspiração veio do constitucionalismo inglês, mas na administração, pautada por Portugal e França, e até mesmo em certas fórmulas angloamericanas, (justiça de paz, júri), além de uma limitada descentralização provincial (CARVALHO, 2005, p.90-91).

Enquanto na imprensa paraibana as ideias francesas tiveram mais repercussão, seja na quantidade de periódicos, seja na diversidade de assuntos abordados, na capital pernambucana $^{3}$ encontramos também referências americanas e alemãs (o Jornal do Commercio [1872], publicado pela Associação de Guarda-Livros de Pernambuco, trazia o editorial de primeira página escrito em português e vertido para o francês, o inglês e o alemão), dado o pensamento dos intelectuais que encabeçavam as publicações. Essa diferença é intrigante, se considerarmos a proximidade geográfica e o intenso trânsito de pessoas entre as duas províncias.

Consideremos ainda $O$ Americano $^{4}$, publicação empreendida com o intuito quase exclusivo de difundir o ideário de república dos Estados Unidos, cuja constituição, assim pensava, deveria ter os princípios adotados pela Carta Magna brasileira. Nesse contexto de tensões, no qual a monarquia era revista, "a república ideal era sem dúvida a do modelo norteamericano." (CARVALHO, 2005, p.93). A justificativa da propaganda do ideário de outro país que não a França é apresentada na seção Idéas Americanas:

No Brazil já se vai fallando muito da America, e das instituições americanas. Ainda bem.

Atè certo tempo não pareciamos um povo americano. Nossos usos, costumes, instituições, leis, regulamentos, tudo era calculadamente feito e combinado á européa.

Infelizmente para nós o espirito europeo, que nos domina, é o de peior quilate. A nossa constituição política, outhorgada por d. Pedro I sob a apparencia de um governo livre, occulta a organisação de uma monarchia absoluta, tendo o povo apenas uma parte illusoria no poder legislativo. As nossas leis e regulamentos são copiados do que a França possue de mais centralisador, quando não os encontramos já traduzidos em Portugal. (Jornal O Americano, edição 3, 15/05/1870)

No Brasil oitocentista, a América e as instituições americanas exerceram influência sobre alguns intelectuais, como o jurista alagoano Tavares Bastos, adepto do liberalismo americano e propagandista de um sistema de ensino aos moldes estadunidenses (HAMDAN, 2014). Se num primeiro momento a França parecia dominar o pensamento ideológico brasileiro, paulatinamente - e em busca de respaldo - os Estados Unidos aparecem como alternativa.

\footnotetext{
${ }^{3}$ A Lanterna de Diógenes (1883) tinha por epígrafe o lema da Revolução Francesa: Liberdade, Igualdade e Fraternidade.

${ }^{4}$ Pareceu-nos pertinente apresentar particularmente o caso de $O$ Americano com o intuito de ampliar nosso objeto de pesquisa, na perspectiva de que em um mesmo contexto histórico diferentes ideias são postas em campo, e esses pensamentos, embora aparentemente hegemônicos, convivem em busca de legitimação sem que um anule, necessariamente, o outro.
} 
O que $O$ Americano repudia na Europa é o mesmo que rejeita (e combate) aqui no Brasil: a organização política centrada no imperador. Mesmo com uma constituição, o povo não tinha, acreditava, o poder que se imaginava conquistado com a proclamação da república. Apesar de citar "usos, costumes, instituições, leis, regulamentos", a questão central que incomoda o jornal é a política, fundamentalmente a constituição.

De fato, a constituição a que ele se refere (1824) foi redigida sob influência da Constituição Francesa de 1791, que resumia as principais conquistas da revolução de 1789. A insatisfação expressa em $O$ Americano tem foco nos poderes conferidos ao imperador. Talvez o desejo dos mentores do jornal fosse que nossa constituição, a exemplo da americana, exprimisse um meio-termo entre as tendências estadista (defendida por Thomas Jefferson, pregava autonomia política para os estados membros da federação) e federalista, cujo intuito era preservar a união política dos estados, fortalecendo, por consequência, o poder central.

Das fontes consultadas na Paraíba, encontramos apenas um registro da circulação do modelo americano na província, o que nos leva à conclusão de que os jornalistas paraibanos tinham conhecimento de outras experiências de modernidade que não a francesa. A frequente aparição da França, portanto, é fruto da escolha desses redatores.

Esse registro coube a $O$ Conservador, autointitulado "essencialmente católico". É sob a ótica da religião professada que o jornal representa os Estados Unidos, a quem vê como ameaça. Essa ameaça estaria caracterizada pela perda de poderes pela Igreja, ante a iminente separação entre ela e o Estado.

\section{Uma lei dos Estados-Unidos.}

Sendo muito comum ouvir, nos que advogam a separação da Igreja do estado, e combatem a decretação de uma religião official, citar com emphase a Confederação Americana já como o emporio da liberdade de consciencia, já como um victorioso exemplo da completa indifferença que mantêm os poderes publicos d'aquella republica em assumptos religiosos, cumpre que fastiguemos o desplante com que, abusando-se da ignorancia geral, se sustenta tao falsa doctrina.

Para completo effeito basta-nos transcrever em sua integra, desde o preambulo, uma lei recentemente votada, por quasi unanimidade, em ambas as casas legislativas, ou por outra pelo congresso. Por ella verse-ha que, longe de ser indifferente aos preceitos do catholicismo, o sabio aeropago Americano prescreve rigores, desconhecidos no próprio Brasil, contra aquelles que os não observam com ponctualidade e dedicação. (Jornal $O$ Conservador, edição 4, 29/09/1875)

A depender do posicionamento dos jornais, a representação da realidade varia de modo a preservar interesses. Enquanto em $O$ Americano os Estados Unidos figuram na seara de países exemplares, em $O$ Conservador ele é mal visto e reduzido ao aspecto religioso. É essa a face americana que o jornal paraibano parece querer ocultar. Ao optar por trazer ao debate social uma lei dos Estados Unidos, O Conservador reduz a questão ao âmbito religioso, que deseja preservar. Ele prossegue apresentando a lei: 
Eis a lei:

"A sanctificação do domingo é:

" 1 . Uma cousa de interesse público;

“2. Um allivio util ás fadigas do corpo;

“ 3. Uma occasião de cuidar nos deveres pessoaes e reparar os erros que affligem a humanidade;

“ 4. Um motivo particular de honrar, na própria casa e na igreja, o Deos Creador e a Providencia do universo;

“ 5. Um estimulante para o homem consagrar-se ás obras de caridade, que fazem o ornamento e a consolação da sociedade.

"Considerando, que ha incredulos e homens inconsiderados que, desprezando seus deveres e as vantagens que procura a humanidade a sanctificação do domingo, ultrajam a sanctidade desse dia, entregando-se a toda a sorte de prazeres e applicando-se aos seus trabalhos;

"Que um tal procedimento é contrario a seus interesses de christãos e perturba o espirito dos que não seguem este máo exemplo.

"Que taes pessoas fazem mal a toda a sociedade, introduzindo em seu seio tendencias de dissipação e de habitos immoraes.

"O senado e as camaras decretão:

“1. É prohibido, no domingo, abrir os armazens e as lojas, occupar-se em qualquer trabalho, assistir aos concertos, bailes ou theatros, sob pena de multa de 10 a 20 shillings por cada contravenção.

“ 2. Nenhum recoveiro ou viajante poderá, sob a mesma pena, emprehender uma viagem no dia de domingo, salvo o caso de necessidade, segundo o juizo da policia.

“ 3. Nenhum hotel ou botequim poderá abrir se no domingo ás pessoas que habitão a communa, sob pena de uma multa ou fechamento do estabelecimento.

“ 4. Aquelles que, a não ser por molestia ou motivo sufficiente, deixarem de ir a igreja durante tres mezes, serão condemnados a uma multa de 10 shillings.

“ 5. O que praticar acções inconvenientes nas proximidades ou interior da igreja pagara de 5 a 40 shillings de multa.

"A execução do presente decreto é confiada aos empregados de policia, escolhidos todos os annos pelas communas."

(Jornal O Conservador, edição 4, 29/09/1875)

A lei em debate é apresentada muito vagamente, com dados inconsistentes. Não sabemos de que lei se trata nem em que contexto de produção ela foi aprovada, como diz $O$ Conservador. Os Estados Unidos, desde a colonização, tinham por credo o protestantismo, na doutrina da predestinação. Por isso, é pouco provável essa lei ter sido dirigida a católicos americanos, tendo em vista que a santificação do domingo é comum às duas vertentes religiosas. Acreditamos que essa lei foi descontextualizada com vistas a ocultar detalhes que comprometeriam "a verdade" a ser vendida pelo jornal. 
Nessa modernidade racional, técnica, centrada na tecnologia, na máquina, no domínio da natureza, na superioridade do artificial (criado pelo homem) sobre o natural, a comparação entre as nações era uma forma de obter parâmetros de ideias bem sucedidas e de associar-se à imagem que aquele determinado país portava. Movidos pela corrida "rumo ao desenvolvimento", em que os países querem se afirmar "no campo do progresso", eles se tomam uns pelos outros.

No editorial abaixo, $O$ - Conservador $^{5}$ reúne referências a dois modelos de modernidade que, apesar de conviverem, costumavam ser excludentes: ou se era francês ou se era americano. O objetivo do jornal não é comparar esses modelos; o que importa é o quanto cada um é bem sucedido na defesa e difusão de seu projeto político. Embora as ações desses governos sejam tomadas como experiências exitosas que poderiam ser reproduzidas no Brasil, nossos articulistas tendem, em geral, a ignorar a diferença entre a realidade desses países e a do nosso.

Palco divulgador de ideias tão diversificadas, o jornal é o elemento-chave articulador dessas questões em circulação na modernidade. Elemento símbolo da modernidade, a imprensa ou tipos móveis surgiu no século XV pelas mãos do tipógrafo alemão Johannes Gutenberg. O aparecimento dos jornais, datado desde finais do século XVII, foi impulsionado pela invenção desses tipos, que permitiam impressão em larga escala, e pela emergência da esfera pública burguesa, que necessitava de informações para a realização de trocas comerciais.

O jornal passou a representar, assim, um novo espaço para o debate público, que para ele foi deslocado das praças e de outros ambientes de sociabilidade - salões, cafés, clubes. No Iluminismo, foi um suporte utilizado por personas como Voltaire, Diderot e Mirabeau para questionar a organização social. Durante a Revolução Francesa, de inspiração Iluminista, foi fundamental para seu encaminhamento.

Nas fontes que compõem este trabalho, a imagem compartilhada pelos periódicos, em geral, é a da imprensa como difusora de luzes - sinônimo de conhecimento. Exemplo disso é o jornal paraibano Correio Noticioso ${ }^{6}$ :

\section{A Imprensa}

Estamos no ultimo periodo do seculo XIX.

A humanidade contempla extasiada a locomotiva do progresso, que caminha...

Seu traçado é infiito: a imprensa, seu pharol.

Ondas de luz derrama a imprensa por toda a parte.

Luz benefica, luz sublime, que projecta nas telas do futuro as glorias do passado.

Christo, o Rei Divino, pregou - a igualdade.

Guttemberg, o nobre humano, proclamou - a liberdade.

Já no Sinay a Omnisciencia havia legislado nas duas paginas do grande

\footnotetext{
${ }^{5}$ Dirigido por Caetano Alves de Souza Filgueiras, tinha por epígrafe Deus e a lei, a sciencia e a grei. Advogado, professor, dramaturgo, poeta, membro do Instituto Histórico Geográfico Brasileiro (IHGB), Caetano Filgueiras era natural da Bahia e foi redator de jornais também no Rio de Janeiro. Em 1862, foi nomeado presidente da província de Goiás pelo imperador D. Pedro II.

${ }^{6}$ Publicado na tipografia de Joaquim João da Silva Braga, sobre quem não nos foi possível recolher detalhes.
} 
livro dos povos.

A mae-vos como irmãos em honra de nosso Pai Eterno.

E á imprensa, como semi-dea do progresso, coube a sublime missão de reproduzir o edicto de um Deos.

Baluarte das modernas idéas, tende ella á realisação dos grandes principios civilisadores.

Os mais arrojados tentamens do homem hão echoado nos prélos.

Em 1440 disse o homem ao mundo:

- Lêde!

E por toda a parte soletrou-se o nome da imprensa e irradiou a luz benefica da publicidade.

E as gloriosas tradições de remotas eras, que já se iam sumindo, sob camadas e camadas de pó dos séculos, reviveram para sempre ao livre bafejo de Gottemberge - bafejo que é como um sello de eternidade.

Não é o bronze de Moguncia, nem os festejos centenares de Strasburgo que nos relembra a historia d'este genio.

Cada folha de um livro, cada pagina de um jornal, nos canta um poema em honra do seculo XV, nos recita uma epopea em louvor do inspirado filho da Germania.

\section{Sagrada missão a da imprensa...}

(Do "Trabalho." S. Paulo.) (Jornal Correio Noticioso, edição 594, 07/12/1876; ênfase adicionada)

A aceleração do tempo histórico, presente na imagem do progresso como uma locomotiva, confere ao homem moderno o posto de senhor do seu destino, independente de uma interferência divina. O progresso, fruto da ação humana, à semelhança de uma locomotiva ${ }^{7}$ - veloz, sempre em frente -, tem na imprensa um farol, que seria, assim como a educação, uma promotora de civilização.

Projetar nas telas do futuro as glórias do passado implica partir de um espaço de experiência que não é mais valorizado no tempo moderno. Para Koselleck (2006), a modernidade vai desprezar o passado como referencial para a construção do futuro. No horizonte de expectativa, passado e presente dão lugar a uma busca incessante pelo que está por vir.

O Correio Noticioso apresenta, diante disso, a crença num passado de glória que precisa ser perpetuado. O próprio Gutenberg é um deus a quem caberia essa responsabilidade, cuja execução seria dada pela imprensa. Na ótica moderna, conforme exposto acima, essa concepção mudou. $\mathrm{O}$ tempo é baseado na expectativa, não mais na experiência.

Na leitura do Correio Noticioso, percebe-se, assim, uma mescla entre elementos modernos e religiosos - que tão bem caracterizou o modo de experimentar a modernidade no Brasil -, tanto na concepção de tempo, quanto na construção das figuras de Cristo e de Gutenberg. Este, assim como o outro, é divinizado. Como figura moderna, o valor de Gutenberg centra-se na tarefa de difundir as ditas luzes e, por conseguinte, conduzir a locomotiva do progresso via imprensa.

\footnotetext{
${ }^{7}$ Walter Benjamin também utilizou a imagem da locomotiva como representante do progresso em marcha, porém, uma locomotiva descontrolada que conduziria o homem à destruição.
} 
A história da imprensa, nessa concepção, é escrita por homens, a quem coube o domínio da palavra e, consequentemente, a garantia de expressar ideias nesse novo espaço de legitimação da opinião pública. No século XIX, porém, as mulheres vão, paulatinamente, compondo o corpo de escritores que se comunicam publicamente via jornal, entre elas a francesa George Sand.

\section{O progresso técnico no espaço público da imprensa}

Retomando nossa discussão sobre a modernidade guiada pela comparação entre as nações, apresentamos ao leitor o registro dado pelos periódicos às exposições universais, locus onde a modernidade se configura em espetáculo, eventos nos quais essa modernidade é materializada em artefatos que exprimem a técnica das produções industriais e alimenta a acirrada competição entre os povos na corrida rumo ao progresso.

Palcos de divulgação de ideias de modernidade e de modos de vivê-la, as exposições universais $^{8}$ da indústria surgiram após a Revolução Industrial no país que a encabeçou, Inglaterra, em 1851, por iniciativa do príncipe Albert, marido da rainha Victoria. Tiveram propósitos sobretudo econômicos - divulgar e internacionalizar os produtos industrializados produzidos na época -, funcionando como vitrines do progresso das nações expositoras.

Celebravam o que havia de mais moderno na produção industrial europeia, as máquinas, as facilidades da vida moderna (via auxílio das máquinas), as possibilidades e técnicas de alguns materiais, como ferro, aço e vidro, o progresso das nações ${ }^{9}$, a racionalidade e criatividade humanas, a ciência, o novo. Compreendemos essas exposições como epíteto da modernidade, capaz de agregar muitos outros que também se referem a essa época histórica.

A partir delas, "o progresso era algo passível de ser verificado: máquinas novas, inovadores processos, inventos surpreendentes modificavam o mundo" (PESAVENTO, 1997, p.15). Estavam afirmados, assim, o pretenso domínio do homem sobre a natureza, a transformação do natural em artificial, a visão positiva do progresso, o qual "sublinha as diferenças entre os países que se apresentavam nesses eventos.” (HEIZER, 2010, p.2)

Se para a Europa as exposições funcionavam como vitrines do progresso, dando a ver o que havia de melhor na produção industrial, para o Brasil a participação em exposições figurava como tentativa de desvincular do país a imagem de exotismo ou de atraso, posta sua condição de escravagista e agrário. Enquanto a Europa buscava (a)firmar sua soberania industrial, o Brasil travava um embate para também parecer moderno.

Na análise de Pesavento (1997, p.17), o Rio de Janeiro, então sede da Corte, "era a porta de entrada da modernidade para o país, bem como o centro irradiador de uma certa imagem da nação e de suas potencialidades para os grandes certames que se realizavam no exterior". Sem discordar da autora, acreditamos também que, apesar de a modernidade adentrar o país pelo Rio de Janeiro, isso não impedia que outras províncias tivessem - e fornecessem - acesso, ainda que pela imprensa, à experiência moderna.

\footnotetext{
8 Essa universalidade seria assegurada pela abrangência de itens expostos no evento e pela internacionalização (participação de nações estrangeiras).

${ }^{9}$ Quanto mais industrializado fosse o país, assim pensavam, mais avançado ele seria. Por isso essa corrida desenfreada para exibir máquinas e produtos delas derivados. A necessidade de afirmação se dá também pela comparação entre as nações e está relacionada à competição pelo domínio do mercado capitalista. Para mais informações, ver Koselleck (2006).
} 
Na Paraíba, o jornal $O$ Liberal Parahybano é representativo nesse sentido, tendo em vista ter sido um espaço frequente de discussão dessas exposições universais. Em suas edições, de circulação semanal, ele mantém uma seção não assinada intitulada Correspondencia, na qual um representante internacional reporta acontecimentos ocorridos sobretudo na França. Na edição de 30/08/1879, a referida coluna informa os leitores sobre a abertura da Exposição Universal de Paris de 1878.

Essa exposição, que teve Agricultura, Artes e Indústria por tema, foi a terceira exposição universal abrigada na capital francesa e pensada com a finalidade de demonstrar ao resto do mundo a recuperação econômica e a pujança industrial da França depois da crise causada pela derrota na Guerra Franco-Prussiana de 1870. Acompanhemos o primeiro trecho da narrativa:

A cerimonia era para as duas horas da tarde. Cheguei ao meio-dia. Os trabalhos não estão de todo terminados e a installação dos expositores não é completa.

Entro, e deparo logo com a cabeça da magestosa estatua da Liberdade illuminando o mundo, cabeça tão volumosa que varias pessoas podem entrar n'ella sem difficuldade. Nos jardins estão os novos productos agricolas e as machinas. Ahi é que se procederá todos os dias a experiencias de illuminação eletrica, extinção instatanea dos incendios, navegação aerea etc. N'um dos lados ergue-se o pavilhão do Presidente da Republica, elegante construcção composta de varios salões e de um formoso jardim de inverno. Atravesso rapidamente as compridas galerias, apinhadas de maravilhas que terei tempo de examinar mais tarde, e estou presente á ceremonia de inauguração, que foi feita pelo senador Julio Simon, o qual pronuncia entre applausos um discurso admiravel.

Á noute, os principaes espositores, os representantes da imprensa e o jury da Exposição assistirão a um lauto banquete. (Jornal O Liberal Parahybano, edição 47, 30/08/1879; ênfase adicionada)

De autoria do escultor francês Frédéric Auguste Bartholdi, a cabeça da Estátua da Liberdade foi o símbolo dessa exposição e tinha como objetivo "expressar o pensamento de amizade duradoura entre os povos. A cabeça é um lugar panorâmico construído para receber visitas. Foi oferecida aos Estados Unidos em 1886, em homenagem à Constituição Americana." (GOMES, PICCOLO \& REY, 2011, p.5)

A estátua, cuja tocha é um representativo do primeiro pilar da Revolução Francesa, tem a cabeça descrita pelo repórter como majestosa, cheia de luz, volumosa. Chamamos a atenção para os adjetivos que a caracterizam porque esses qualificativos nos dizem muito da opinião do redator do texto e do jornal no qual a notícia está inserida.

A cabeça da estátua - a racionalidade a ela implícita - ilumina o mundo com suas ideias. Centro difusor de modernidade, a França, sem dúvida, encontrou meios para distribuir seus ideais, os quais eram apropriados pelos povos que com eles tomavam contato. Para os Estados Unidos, enviou a estátua bartholdiana. 
Figura feminina, A Liberdade Iluminando o Mundo encarna também um outro lugar tecido para o feminino no século XIX, qual seja o de simbolizar o novo. Em oposição a ícones masculinos, significando dominação e atraso, o elemento feminino foi escolhido pelos revolucionários franceses (conferir a famosa pintura A Liberdade Guiando o Povo, de Eugène Delacroix, na qual a mulher é o epíteto da própria liberdade) para abrigar a liberdade, a república e a pátria. Assim como a imprensa, com sua tocha, ela ilumina os caminhos guiando os povos na senda do progresso.

Sobre a cerimônia de inauguração, destacamos que o governo brasileiro se fez representar nas exposições universais desde 1862, quando se apresentou em Londres. De acordo com Pereira (1992, p.2), “desde as duas primeiras exposições universais, realizadas respectivamente em Londres, 1851, e Paris, 1855, os europeus começam a entrar em contato com algumas matérias-primas e produtos manufaturados brasileiros."

Mais do que se inserir no circuito de nação civilizada, o Brasil via na participação dessas exposições um modo de vender seus produtos agrícolas, de alargar suas fronteiras comerciais. Nesse novo contexto pós Revolução Industrial, era importante compor o mercado de negócios. Se o Brasil não podia exibir máquinas ou produtos industrializados, se aproveitava desse cenário para atrair investidores e abastecer os países produtores com as matérias-primas de que eles precisavam.

Nesse sentido, era presença natural nas exposições não só empresários - que recebiam apoio do governo para custear as despesas decorrentes do evento -, mas também políticos e jornalistas. Por outro lado,

Mesmo quando, por razões econômicas ou políticas, o governo não organiza pavilhões específicos reunindo os produtos brasileiros constituindo uma representação oficial -, empresários, homens de negócios, cafeicultores, cientistas, engenheiros e arquitetos participam de colóquios internacionais - como os realizados pela primeira vez no âmbito das exposições de Viena, em 1873, e Paris, em 1878 - ou organizam às suas próprias expensas a exposição dos seus produtos, como ocorre, por exemplo, na exposição de 1889, igualmente em Paris. (PEREIRA, 1992, p.2)

Continuando a descrição do evento, prossegue o correspondente:

Ha mezes, em Londres, ou melhor, nos arredores da grande capital, inaugurou-se uma "Exposição permanente de Bellas-artes e industria", no Palacio de Crystal.

Então não seria possivel decidir os nossos patricios a figurarem n'esses utilissimos e pacificos certamens? Então esses grandes concursos, em que se apresentão homens de todos os paizes, não podião ser para nós os Brazileiros, uma occasião de tornarmos mais conhecidos os nossos productos? Imaginem que em todas essas Exposições o Brazil figura-se. Em breve, os seus productos serão mais apreciados, as 
encommendas se multiplicarão, o trafico augmentaria, e o nosso commercio acharia uma nova sahida. Pouco a pouco o café, o algodão, o assucar, os couros seccos e salgados, a borracha, o fumo, o mate, o cacao, a cachaça, a tapioca, as madeiras, a crina e a lã, o ouro e os diamantes, a popaya e todos os demais productos das diversas provincias serião devidamente apreciados, e as transacções aumentarião de um modo -- (ilegível)

Para realisar tal progresso é --- (ilegível) o concurso do governo. Basta os particulares ficarem compenetrados d'essa necessidade, e dirigirem-se pessoalmente aos organisadores d'essas exposições, os quaes, mediante diminutissimas quantias hão de encarregar-se de installar as suas amostras, transmitindo-lhes todas as informações necessarias. É o que fazem os demaes paizes. (Jornal $O$ Liberal Parahybano, edição 47, 30/08/1879; ênfase adicionada)

No imperativo de uma autoafirmação, as exposições universais precisavam de símbolos que "encarnassem" a modernidade que elas representavam. Assim, cada cidade-sede erguia um monumento ícone para abrigar o evento. Na primeira delas, em Londres, veio a público o Palácio ${ }^{10}$ de Cristal, "que com uma moderna construção de ferro e vidro demonstrou ao mundo do que era possível a feliz combinação da ciência, da técnica e da indústria." (PESAVENTO, 1997, p.53)

Torna-se clara a compreensão da intencionalidade associada à construção dessas obras quando tomamos a própria exposição como um espetáculo. Assim, a exposição "[...] não é somente a apresentação de técnicas novas ou laboratório de inovação, ela é também representação. Ela participa da ostentação. [...]" (CARRÉ, 1989, p.35)

$\mathrm{Na}$ acirrada disputa entre as nações pelos títulos de mais moderna e de mais civilizada, construções como o Palácio de Cristal eram erguidas para demonstrar não só as capacidades do engenho humano, mas para afirmar a soberania de um povo. A utilização de ferro e vidro e os processos técnicos empregados consolidam também o espírito da Revolução Industrial, com a produção de peças em série e pré-fabricadas, o que significa controle e otimização (redução) do tempo, força, solidez, durabilidade.

$\mathrm{O}$ ferro foi o primeiro material artificial empregado na arquitetura moderna (BENJAMIN, 1985). "Evita-se o ferro nas moradias, mas ele é empregado nas galerias, salas de exposições e estações de trem - construções que serviam para fins de trânsito. Simultaneamente se amplia o campo de aplicação arquitetônica do vidro" (BENJAMIN, 1985, p.32). Num equilíbrio de forças, enquanto o ferro abriga as mercadorias, representando a racionalidade, a força e a solidez, o vidro, com sua translucidez, as expõe e as protege. Não à toa ter sido a matéria-prima da Torre Eiffel ${ }^{11}$, fruto dessas exposições e presente até nossos dias.

10 Após a exposição de 1851, o Palácio foi trasladado a outra área de Londres para servir de abrigo a concertos e outras atividades culturais, até ser destruído por um incêndio em 1936. No Brasil, inspirou a construção do Palácio de Cristal de Petrópolis (RJ, 1884), cuja estrutura pré-montada foi fabricada em Paris, e da estufa do Jardim Botânico de Curitiba (PR, 1991).

${ }^{11}$ Construída especialmente para a exposição de Paris de 1889, em comemoração ao centenário da Revolução Francesa, o que revela o caráter também nacionalista desses eventos. 
Apesar de produzida apenas com ferro, a transparência da obra, que em outras construções é garantida pelo emprego do vidro, é mantida. Na avaliação de Pesavento (1997, p.55), a Torre, “apontando para os céus de Paris, encarnava não só uma nova concepção de mundo, mas se constituía num próprio monumento à racionalidade, ao moderno e ao progresso técnico", ou seja, ela é a materialização das ideias de um tempo.

A Torre ${ }^{12}$ simboliza também o fálico, sempre ereta, apontando em direção ao infinito, rompendo as barreiras do tempo, um representativo de soberania que a França projetava de si para o resto do mundo. Símbolo de um século - e hoje da própria capital francesa -, a Eiffel, com 300m de altura, era a construção mais alta de seu tempo, fato que afirmava não só o desenvolvimento da arquitetura, mas o triunfo da racionalidade humana.

Aprovando o exemplo inglês, que teve a iniciativa de inaugurar uma exposição permanente de belas artes e indústria no Palácio de Cristal, o jornalista convoca os brasileiros a tomarem uma atitude, haja vista a utilidade (de oportunidades comerciais) desses certames, concursos que representavam ferrenhas disputas entre as nações que ali estavam por mercados consumidores, concorrendo ao posto de soberania.

Esse pensamento, que se quer único pelo redator, não era, todavia, unânime. Rui Barbosa, por exemplo, era um opositor tenaz à famosa tradição agrária brasileira, já lutando por um espírito mais científico e industrial dentro do Brasil em seus pronunciamentos políticos. Para ele, insistir na tradição agrária significava manter o país em situação de atraso em relação àqueles já industrializados.

As exposições eram também lugar de encontro, no qual as pessoas circulavam contemplando vitrines. Esses espaços eram estratégicos para a apresentação de novidades e para despertar o desejo de comprar, movimentando o mercado consumidor. Não é à toa que em algumas ocasiões foram conhecidas como festa e espetáculo. Alguns autores citam também o caráter pedagógico desses eventos (ver Kuhlmann Júnior, 2001; Pesavento, 1997; Heizer, 2010).

Diante disso, podemos falar de uma exaltação à produção mecanizada ou fetichização da mercadoria, conforme aponta Walter Benjamin (1985), para quem as exposições eram um centro de peregrinação para esse culto. Como lugar de sociabilidades, as exposições seriam, por excelência, o ambiente do dandy ou flâneur, pela classificação do poeta francês Charles Baudelaire. O dandy seria alguém que anda a esmo pelas ruas, a contemplar vitrines. Nas palavras de Pesavento (1997, p.28), ele é "um diletante, um vagabundo, um boêmio, que não procura atingir outro fim senão o de celebrar por tudo e sempre a glorificação das aparências, da beleza e das sensações."

Juntamente com o dandy, era possível encontrar empresários e curiosos, que representavam as multidões maravilhadas desfilando "pelas exposições, admirando os prodígios da engenhosidade do homem e atraídas pela mística do novo, do fantástico e do exótico" (PESAVENTO, 1997, p.45). O Guide Bleu du Figaro et du Petit Journal, publicado para orientar os visitantes da Exposição Universal de Paris de 1889, assim se pronunciava:

\footnotetext{
12 Objeto para ser olhado, como qualquer outra mercadoria exposta nas vitrines das galerias, a Eiffel não foi erguida com vistas a uma finalidade específica. Quando construída pelo engenheiro e arquiteto francês Gustave Eiffel, não aspirava à perenidade e foi rejeitada por muitos parisienses.
} 
Com que espírito é preciso visitar a Exposição? É preciso vê-la com o mesmo espírito que presidiu a sua organização: é preciso vê-la para se instruir e para se divertir. Ela é para todo mundo, para todas as idades, para os sábios, assim como para os menos instruídos, uma incomparável 'lição de coisas'. O industrial aí encontra os modelos dos quais ele saberá aproveitar. $\mathrm{O}$ simples passante aí toma uma idéia geral e suficiente das maravilhas, sempre em progresso, da indústria moderna [...] (Guide Bleu du Figaro et du Petit Journal. Paris. Exposition de 1889, p.5)

Na citação é evidente o apelo ao caráter pedagógico e lúdico das exposições, que podiam servir, a depender dos interesses, a todo público, inclusive ao flâneur (o simples passante), que pode se atualizar das últimas novidades. Estas, referidas como "maravilhas, sempre em progresso" nos fazem refletir sobre algumas questões típicas da modernidade.

A primeira delas é a recorrência a palavras que exprimem grandeza e fuga ao ordinário, ao comum das coisas, pois, sob a lógica moderna, o que está por vir é, necessariamente, melhor do que o passado, que deve, por sua vez, ser sempre superado. Vivese, tal como postula Koselleck (2006), uma aceleração do tempo histórico, que nega o passado e passa pelo presente em busca do futuro.

A segunda é a apropriação do termo "progresso", que, ao se remeter à ideia de uma marcha incessante, do presente para o futuro, traria como consequência uma realidade, por si só, maior e melhor que a anterior. Essa aposta no progresso ilimitado, tipicamente racionalista, estaria relacionada, segundo Pesavento (1997, p.44), à "confiança nas potencialidades do homem no controle da natureza", à "fé nas virtudes da razão" e ao "caráter positivo das máquinas."

Observe-se que o pretenso controle da natureza se dá por meio da máquina, tendo o homem como guia, ao transformar o natural em artificial. Nesse sentido, o artificial, por ser produto do trabalho humano, adquire maior valor de apreciação do que o natural, que não foi moldado pelo intelecto. A fé é dirigida do homem para o próprio homem, capaz de conduzir a si mesmo pelas virtudes da razão. A crença e a fé válidas são apenas aquelas investidas para a racionalidade humana, que tem o progresso como meta.

Nesse debate, insere-se ainda o historiador John Bury, para quem a ideia do progresso é "uma teoria que contém uma síntese do passado e uma previsão do futuro. Baseia-se numa interpretação da história que considera o homem caminhando lentamente. [...] em uma direção definida e desejável e se infere que este progresso continuará indefinidamente." (BURY, 1971, p.6-7)

Nesse aspecto de compreensão do progresso, as ideias de Bury (1971), Pesavento (1997) e Koselleck (2006) parecem bastante aproximadas, ao comungar de valores como foco na racionalidade humana, capacidade de transformar o natural em artificial, soberania da máquina, avanço social e manipulação do futuro, que "se antecipa como uma conquista assegurada.” (PESAVENTO, 1997, p.46) 


\section{Considerações finais}

Iniciadas no século XIX, as exposições internacionais existem até hoje. Segundo Gomes, Piccolo \& Rey (2011, p.8), perderam o brilho inicial com a eclosão da Primeira Guerra, "tornando-se mais espaçadas e menos divulgadas". Naturalizadas as inovações tecnológicas, foi-se o caráter de promotoras da ciência e da técnica.

A Exposição Universal e Internacional de Paris em 1900 marcou o final das exposições universais com esse propósito, pois "as invenções tecnológicas apresentadas nas exposições anteriores tinham passado a fazer parte da rotina diária, como o telefone, o cinema e o automóvel. Além do mais, a indústria tinha-se desenvolvido e especializado de tal forma que já não podia ser retratada numa só exposição" (LOPES, 2007, p.103). No estágio da modernidade em que se encontravam já no início do século XX, esse tipo de exibição não era mais exigido. Os países passaram a se basear em outros referenciais e criaram outras formas de dar a ver a sua pujança.

Considerando a imprensa como a nova arena de discussão pública, pólo irradiador de ideias, ela atende às demandas da modernidade de trazer à baila o confronto entre as representações do novo e do antigo, do conservador e do moderno, num período em que esses contrastes buscam legitimação social.

\section{Referências}

AGUIAR, Cláudio. Franklin Távora e o seu Tempo. Ateliê Editorial: São Paulo, 1997.

BENJAMIN, Walter. Paris, Capital do Século XIX. In: KOTHE, Flávio. Walter Benjamin. Rio de Janeiro: Ática, 1985.

BURY, John. La Idea del Progreso. Tradução de Elías Díaz e Júlio Rodríguez. Madrid: Alianza Editorial, 1971.

CARRÉ, Patrice A. Expositions et modernité: Electricité et communication dans les expositions parisiennes de 1867 à 1900. Romantisme, Paris, n. 65, p.37-48, 1989.

CARVAlHo, José Murilo de. Pontos e bordados: escritos de história e política. Belo Horizonte: Editora UFMG, 2005.

CHARTIER, Roger. À beira da falésia: a história entre certezas e inquietudes. Tradução de Patrícia Chittoni Ramos. Porto Alegre: Ed. Universidade, UFRGS, 2002.

GOMES, Ana Carolina; PICCOLO, Priscilla; REY, Ricardo. Exposições Universais: Sociedade no século XIX - NEC (Núcleos de estudos contemporâneos) - UFF. Niterói: UFF, 2011.

HAMDAN, Juliana Cesário. Tavares Bastos e a educação no Império: as palavras e os conceitos. In: VALLE, Ione Ribeiro; HAMDAN, Juliana Cesário; DAROS, Maria das Dores (Org.). Moderno, Modernidade e Modernização: a educação nos projetos de Brasil séculos XIX e XX (vol.2). Belo Horizonte: Mazza Edições, 2014. 
HEIZER, Alda Lúcia. Considerações sobre a participação da América Latina nas Grandes Exposições da segunda metade do século XIX. Revista Eletrônica da ANPHLAC, São Paulo, n. 9, p.1-16, 2010.

KOSELLECK, Reinhart. Futuro Passado: contribuição à semântica dos tempos históricos. Rio de Janeiro: Contraponto-Ed. PUC-Rio, 2006.

KUHLMANN JÚNIOR, Moysés. As grandes festas didáticas: a educação brasileira e as exposições internacionais 1862-1922. São Paulo: USF/CDAPH, 2001.

LOPES, Ana Patrícia Quaresma. Exposições Universais Parisienses Oitocentistas. 2007. 245f. Monografia (Graduação em arquitetura) - FCTUC, Universidade de Coimbra, Coimbra, 2007.

PEREIRA, Margareth Campos da Silva. A Participação do Brasil nas Exposições Universais: Uma Arqueologia da Modernidade Brasileira. Revista Projeto, São Paulo, n. 139, p.83-90, 1992.

PESAVENTO, Sandra Jatahy. Exposições Universais: Espetáculos da Modernidade do Século XIX. São Paulo: Hucitec, 1997.

\section{Fontes}

CORREIO NOTICIOSO. Anno IX. N.:591. Parahyba, 7 de Dezembro de 1876. Disponível em: <http://www.cchla.ufpb.br/jornaisefolhetins/diversos.html>

O AMERICANO. Semanario Politico e de Litteratura. Anno I. N.:3. Recife - Domingo, 15 de Maio de 1870. Disponível em: <http://memoria.bn.br/DocReader/DocReader.aspx? bib=758400\&PagFis=24\&Pesq= PR_SOR_02379_758400>

O CONSERVADOR. Periodico Polymathico. Anno I. N.:4. Parahyba, 29 de Setembro de 1875. Disponível em: <http://www.cchla.ufpb.br/jornaisefolhetins/acervoPERIODICOS_ PARAIBANOS/ 1826\%20A\%201959/O\%20CONSERVADOR_29-09-1875.pdf>

O Liberal PARAhybano. Orgão do Partido Liberal. Anno I. Publicação semanal. N.:47. Parahyba, 30 de Agosto de 1879. Disponível em: <http://www.cchla.ufpb.br/jornaisefolhetins/oliberalparahybano1879.html> 